\title{
On-the-Job Training of Pharmacy Technicians at the Ministry of Health Hospitals in Saudi Arabia
}

\author{
Yousef Ahmed Alomi, (iD The \\ Former General Manager of General \\ Administration of Pharmaceutical \\ Care, The Former Head, National Clini- \\ cal pharmacy and pharmacy practice, \\ The Former Head, Pharmacy R and \\ D Administration, Ministry of Health, \\ Riyadh, SAUDI ARABIA. \\ Saeed Jamaan Alghamdi, General \\ Administration of Pharmaceutical \\ Care, Ministry of Health, Riyadh, \\ SAUDI ARABIA. \\ Radi Abdullah Alattyh, General Ad- \\ ministration of Pharmaceutical Care, \\ Ministry of Health, Riyadh, SAUDI \\ ARABIA.
}

\section{Correspondence: \\ Dr. Yousef Ahmed Alomi,}

The Past General Manager of General Administration of Pharmaceutical Care, The Past Head, National Clinical Pharmacy and Pharmacy Practice, The Past Head, Pharmacy R and D Administration, Ministry of Health, Riyadh, SAUDI ARABIA.

Phone no: +966504417712

E-mail: yalomi@gmail.com

Received: 14-06-2018;

Accepted: 11-07-2018

Copyright: $\odot$ the author(s),publisher and licensee Pharmacology, Toxicology and Biomedical Reports. This is an open-access article distributed under the terms of the Creative Commons Attribution NonCommercial License, which permits unrestricted non-commercial use, distribution, and reproduction in any medium, provided the original work is properly cited.

This is an open access article distributed under the terms of the Creative Commons Attribution-NonCommercial-ShareAlike 4.0 License

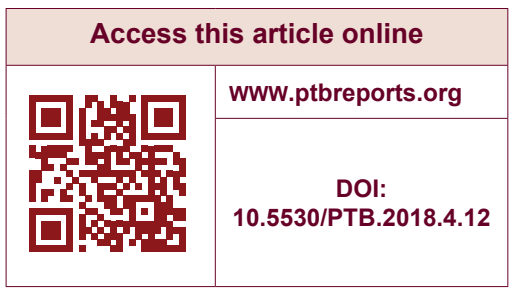

\begin{abstract}
Objective: To demonstrate the pharmacy technicians on the job training at the Ministry of Health of Health hospitals in the Kingdom of Saudi Arabia. Method: It is a retrospective analysis of pharmacy technicians on job training project at the Ministry of Health of Health hospitals. It was within The Pharmacy strategic plan 2012-2020. The study used the modified pharmacy business model system and Project Management Procedure. Results: The pharmacy technicians on job training system established with a defined vision, mission and goals. The system had several resources including human or economic and other described in the review. The continuation of the system assured by risk management model description. Also, the monitoring and controlling of the system as illustrated. The convention to operation project though closing project stage demonstrated in the Analysis. Conclusion: The pharmacy technicians on job training system established within the healthcare system and pharmacy regulations. The pharmacy technicians on the job training system are regularly improving accordingly at all Ministry of Health hospitals in the Kingdom of Saudi Arabia.

Key words: Job, Training, Pharmacy Technicians, Ministry of Health, Saudi Arabia.
\end{abstract}

\section{INTRODUCTION}

Pharmacy technicians provide significant assistance to a pharmacist. They help the pharmacist in providing pharmaceutical care to the patients. In addition, they perform clinical activities such as those of an assistant clinical pharmacist. ${ }^{1-4}$ The pharmacy technicians should register at state board agency at the country level. After registration, they should get continuous medical education to renew their license through the board. There are several training programs available for pharmacy technicians including orientation programs. ${ }^{5}$ In the recent survey conducted in more than 100 Ministry of Health (MOH) hospitals with an emphasis on pharmacy education and training, the authors found that about $31.4 \%$ of the pharmacy technician had received on-thejob training. ${ }^{5}$ The training program consisted of orientations in the pharmacy technicians' system at hospitals and some clinical skills specific for pharmacy technicians. Several reviews have discussed the pharmacy technicians training program. ${ }^{6,7}$ However, to the best of our knowledge, there are no studies conducted in Saudi Arabia which demonstrate the pharmacy technicians training program. The aim of this review was to explore the national pharmacy technicians on-the-job training program at the $\mathrm{MOH}$ in the Kingdom of Saudi Arabia (KSA).

\section{MATERIALS AND METHODS}

\section{METHOD}

This is the description of national pharmacy technician's on-the-job training program. The program was designed for $\mathrm{MOH}$ hospitals in Saudi Arabia. The program was designed by a national committee comprising of expert pharmacists from General Administration of Phar- maceutical Care (GAPC) at $\mathrm{MOH}$ including the author of this study. The regional peripheral training committee consisted of expert pharmacists and technicians. The British University and General Administration of Training were the consultants of the program. The program consisted of two parts: a theoretical and a practical part. The expert pharmacist provided training on the theoretical part in 20 regions. In addition to the central committee from the GAPC, each region had a training coordinator and training preceptors for practical part. The practical part consisted of pharmacy services units including inpatient pharmacy, ambulatory care pharmacy, intravenous admixture, pharmacy inventory management and narcotics and control unit. Each unit had a specific period. The evaluation form was designed for each unit with competency measurements. There was exam by the end of each rotation with minimum pass scores. All evaluation scores should be entered through a unique website and dashboard designed for the general administration of education and training at $\mathrm{MOH}$. The project underwent several phases of development including the initial phase, planning phase, execution phase and monitoring and controlling phase. In addition, it was developed by using the international business model, pharmacy guidelines, project management institution guidelines for a new project. $^{8-11}$

\section{Initial Phase}

\section{Assessment Needs}

Most of the current schools of pharmacy have stopped undertaking the programs of a pharmacy technician. The decision was made by the government for more than 10 years ago. Most of the 
existing pharmacy technicians have graduated several years ago. Moreover, currently, it is hard to find an education and training program for pharmacy technicians. This project was established to meet the factors that are in demand and update the knowledge and skills for pharmacy technicians in the KSA.

\section{Market Analysis}

Most governmental and non-MOH governmental and even probate institutions have special education and training program for pharmacy technicians. The program is designed to prepare new pharmacy technicians for pharmacy practice job. The program is unique and was established for the first time at the $\mathrm{MOH}$ institution and there is no similar program at other institutions in the KSA.

\section{SWOT Analysis}

In this project, we performed a SWOT analysis. The strengths of this project were unified on-the-job training for all pharmacy technicians at the $\mathrm{MOH}$ institutions and prepare additional training programs for pharmacy technicians in the future. The weak points of this project were more workload for preceptor's pharmacist and technicians. The opportunities for this project were the implementation of local and international accreditation standards and future training for pharmacy technicians. The threat points of this project will be privatized healthcare institutions and the program not budgeted in the future.

\section{Planning Phase}

\section{The Scope of the Project}

This is a training program for new graduate pharmacy technicians to join the hospital pharmacy. The program consists of training for a period of 6 months period at several sections of the hospital pharmacy including inpatient pharmacy, outpatient pharmacy, pharmacy store, pharmacy narcotics and controlled medications, intravenous admixture services, extemporaneous preparation with updated education litterateur about the services.

\section{Vision, Missions and Goals}

The vision of this project is to have the best trained and educated expert skilled pharmacy technicians working at the hospital pharmacy. The mission of this project is to provides education and training on the hospital pharmacy practice to newly graduate pharmacy technicians. The goals of this project are to provide the pharmacy technicians with essential pharmacy practice, to gain the pharmacy technicians primary skills demand in practice, to prepare the pharmacy technicians for license practice exam from Saudi Commission of Health Specialties and to keep up-to-date knowledge on the clinical pharmacy knowledge and skills for pharmacy technicians.

\section{Project Description}

This is a 1-year training program, consisting of two phases: the first phase lasts for 6 months when the trainees undertake English course and the second phase involves theoretical and practical training program. Pharmacy technicians should follow the rules mentioned below.

\section{Responsibilities and Accountability of Trainee Technician} from Training Program for Health Institute Graduates: Policy Guide

The trainee's roles and responsibilities shall include the following:

- Complete all preparatory training program-trainee placement prerequisites

- Review and complete with signature the required documentation, as required for continued entry into the Training Program for Health Institute Graduates

- Complete all preparatory classroom and placement-based learning activities in a self-directed learning style to enhance successful learning outcomes and safe practice delivery supported by

- the trainees developing knowledge, skill and judgment/reasoning as grounded in theoretical

- learning

- At all times be professionally responsible

- Orientate self to the organizational, departmental and practice environment

- Orientate self to emergency protocols including fire, safety and CPR

- Orientate self to roles and responsibilities of the various healthcare staff/team membersOrientate self to available human and physical resources

- Orientate self to care and service delivery and documentation protocols

- Orientate self to relevant knowledge and skills related to the specific patient/client population(s) receiving care and service

- Negotiate with the trainer in practice regarding the placement practice hours

- Learn or review the knowledge, competencies, theory and judgment necessary for safe registered technician practice in your domain-specific field

- $\quad$ Practice the knowledge and skill prior to assuming responsibility for care or practices impacting patient/client care

- Apply knowledge/theory to practice

- Build on one's own experience, personal knowledge and wisdom

- Contribute to and support the learning of others

- Develop critical appraisal, problem-solving and critical thinking skills using the reflective process

- Invite and capitalize on learning opportunities in the settings

- Develop personal learning plans related to the program and domain outcomes

- Develop professional relationships with the trainer

- Generate questions in the search of new knowledge in your practice domain area

- Be prepared to discuss the basis of practice with their preceptor / clinical instructor including the trainee's learning plan

- Know (and operate at all times) and work under the policies and procedures of the agency and the training program for health institute graduates

- Constantly check the program's website for any announcements

- Partner with peers to co-construct expertise

- Work collaboratively and interdependently with others

- Be prepared to submit the required evidence of your trainee practice and learningDocument and report in accordance with professional and agency standards

- Maintain confidentiality (e.g. discussing with clients/patients only in appropriate places and with appropriate people)

- Complete all required training program-trainee evaluation and program evaluation requirements and pre- postprogram surveys as requested by the training program and $\mathrm{MOH}$ as a condition of understanding for entry into the training program for health institute graduates

- Knows/acknowledges his understanding that all trainee and program evaluation data including trainee learning outcomes data belongs to the training program and will be used in reports and publications by the $\mathrm{MOH}$

- Understand/know the conditions of the training program of trainee grading are based on the trainee successfully completing all train- 
ing program tests, assignments and activities in accordance with the prescribed deadlines after which a final grade will be determined based on the weighted distribution.

In addition, the pharmacy technicians should be fit with competency for each treating sites explored in Appendix (1).

\section{Plan Cost Management}

All central or peripheral members of pharmacy education and training committee should include the financial budget with meetings hours. The travel and accommodations expenses should be included in the budget. The training preceptors and lectures should include a financial budget.

\section{Execution Phase}

\section{Management Team}

The central and peripheral education and training committee at each region and each hospital should be established. The stakeholder's team should consist of hospital representatives from each section of the pharmacy and should be headed by the pharmacy technician's education and training coordinators. The regional committee should consist of pharmacy coordinators from each regional hospital and be headed by the regional coordinator of education and training in the practice of pharmacy technician. The central committee should consist of GAPC with assessment head, manager of pharmacy development and national drug information center.

\section{Education and Training}

The management team in collaboration with the general administration of education and training departments conducted several sessions for preceptors and pharmacy directors with pharmacy education coordinators. The education session consisted of definitions of the program, training elements, evaluation process and measurement of competencies. In addition, the written exams and electronic training scores documentation system should be conducted. Additional education should be provided for technicians in each region.

\section{Risk Management}

There are six types of risks: budget risk, scope risks, personnel risks, schedule risk, technical risks and quality risks. The project might experience risks such as budget, personnel, schedule and quality risks. The project might experience budget risk due to the unavailability of the budget for education and training of trainees and preceptors. The project may be exposed to personnel risks such as shortage of staff with a high workload of pharmacy technicians training program and not enough preceptors available to train pharmacy technicians. In addition, the pharmacy preceptors may not have received education or training about the project. The project might experience scope risks such as training preceptors' education, training the pharmacy technicians as a pharmacist, or increase the goals of training beyond the scope of the project. The project may be exposed to schedule risks with the delay in the timing of the training program and the extended period of training. The project might be exposed to quality risks due to non-qualified pharmacists being available and the training in the quality pharmacy tools and follow-up missed. The project might be exposed to other technical risks such as unavailability of an electronic system for the documentation, reporting and scoring of pharmacy technicians job.

\section{Monitoring and Controlling Phase}

\section{Project Quality Management}

KPIs should be established for education and training program's followup and to measure the impact of the program. Several KPIs should start with initial starting of the program for instance schedule of the program, evaluation of the trainees and the preceptors, evaluation of lectures and speakers, the impact of pharmacy technicians in prevention medica- tions error, adverse drug reaction and cost avoidance. By the end of the training period, the overall evaluation of the program should be conducted. ${ }^{12,13}$

\section{The Closing of the Project}

Pharmacy technician's on-the-job training at $\mathrm{MOH}$ institution is an essential tool to improve patient care and avoid drug distribution problems in the KSA. The annual report of pharmacy technicians on job training should be done. Education and training programs should be regularly conducted for healthcare providers on the topic of updating new education and training regulations. Further expanded related cost avoidance impact of pharmacy technicians on-the-job training in the future. Annual celebration with the members involved in the project should be done.

\section{ACKNOWLEDGMENT}

None.

\section{CONFLICT OF INTEREST}

The authors declare no conflict of interest.

\section{ABBREVIATIONS}

KSA: Kingdom of Saudi Arabia; MOH: Ministry of Health; KPIs: Key Performance Indicators; PTC: Pharmacy and Therapeutic Committee; RAPC: Regional Administration of Pharmaceutical Care; GAPC: General Administration of Pharmaceutical Care; SWOT: Strengths, weaknesses, opportunities and threats; NUPCO: National Unified Procurement Company for Medical Supplies.

\section{ORCID ID}

Yousef Ahmed Alomi (D) https://orcid.org/0000-003-1381-628X.

\section{REFERENCES}

1. Shane R. Advancing technician roles: An essential step in pharmacy practice model reform. Am J Heal Pharm. 2011;68(19):1834-5.

2. Alomi YA, Alhennawi K, Khayayt N. Pharmacy Technician Workload and Workforce Requirements at $\mathrm{MOH}$ Hospitals during Ten years Mass Gathering Haij (20062015) in Makah Region, Saudi Arabia. J Pharm Pract Community Med. 2017;3(4s).

3. Alomi YA, Alhennawi K, Khayayt N. Clinical Pharmacy Technician Activities and Workforce Requirements at MOH Hospitals during Ten years Mass Gathering Hajj (2006-2015) in Makah and Al-Medina Regions, Saudi Arabia. J Pharm Pract Community Med. 2017;3(4s)

4. Alomi YA, Alhennawi K, Khayayt N. Clinical Pharmacy Technician and Human Resources Requirements at $\mathrm{MOH}$ Primary Healthcare Centers during Ten years Mass Gathering Hajj (2006-2015) in Makah and Al-Medina Regions, Saudi Arabia. J Pharm Pract Community Med. 2017;3(4s):s101-6.

5. Yousef Ahmed Alomi, Saeed Jamaan Alghamdi RAA. National Survey of Pharmacy Practice at MOH Hospitals in Saudi Arabia 2016-2017 : Pharmacy Education and Training. J Pharm Pr Community Med. 2018;4(1):1S-8S.

6. Manasse HR, Menighan TE. Pharmacy technician education, training and certification: Call for a single national standard and public accountability. Am J Heal Pharm. 2011;68(10):869-70.

7. Adams AJ, Martin SJ, Stolpe SF. "Tech-check-tech": A review of the evidence on its safety and benefits. Am J Heal Pharm. 2011;68(19):1824-33.

8. McDonough R. Writing a Business Plan for a New Pharmacy Service. The Dynamics of Pharmaceutical Care: Enriching Patients' Health. 2010;23.

9. Harris IM, Baker E, Berry TM, Halloran MA, Lindauer K, Ragucci KR, et al. Developing a Business-Practice Model for Pharmacy Services in Ambulatory Settings. Pharmacotherapy. 2008;28(2):7e-34e.

10. Sachdev G. Sustainable business models: Systematic approach toward successful ambulatory care pharmacy practice. Am J Heal Pharm. 2014;71(16):1366-74.

11. PMBOK Guide. A Guide to the Project Management Body of Knowledge. Sixth Edit. Project Management Institute, Inc. 2017.

12. Alomi YA, Alghamdi SJ, Alattyh RA. Strategic Plan of General Administration of Pharmaceutical Care at Ministry of Health in Saudi Arabia 2012 - 2022. JPharm Pharm Scien. 2015;1(13):1-8.

13. Alomi Y. National Pharmacy Administration Programs. BAOJ Pharm Sci. $2015 ; 1(2): 1-2$ 


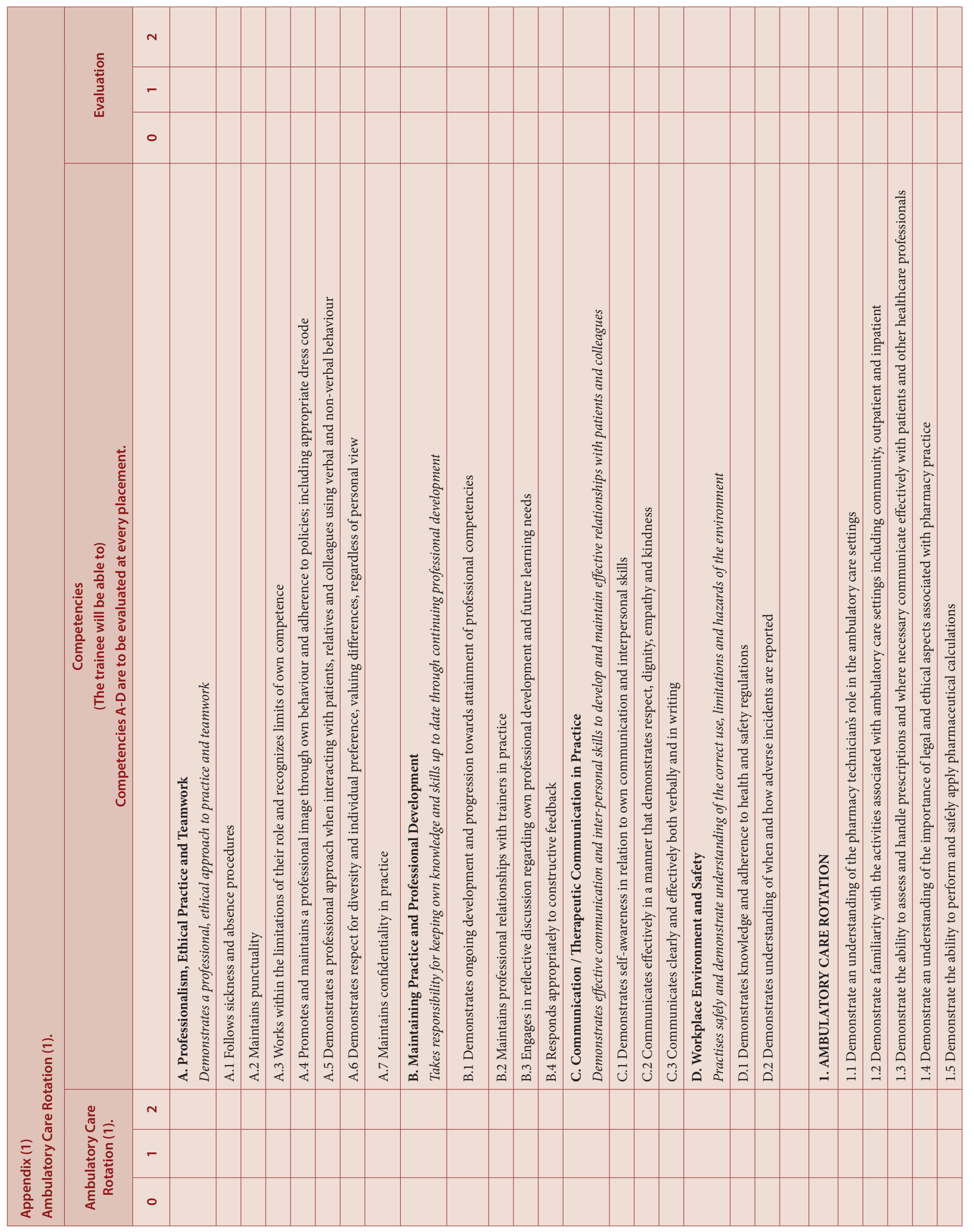




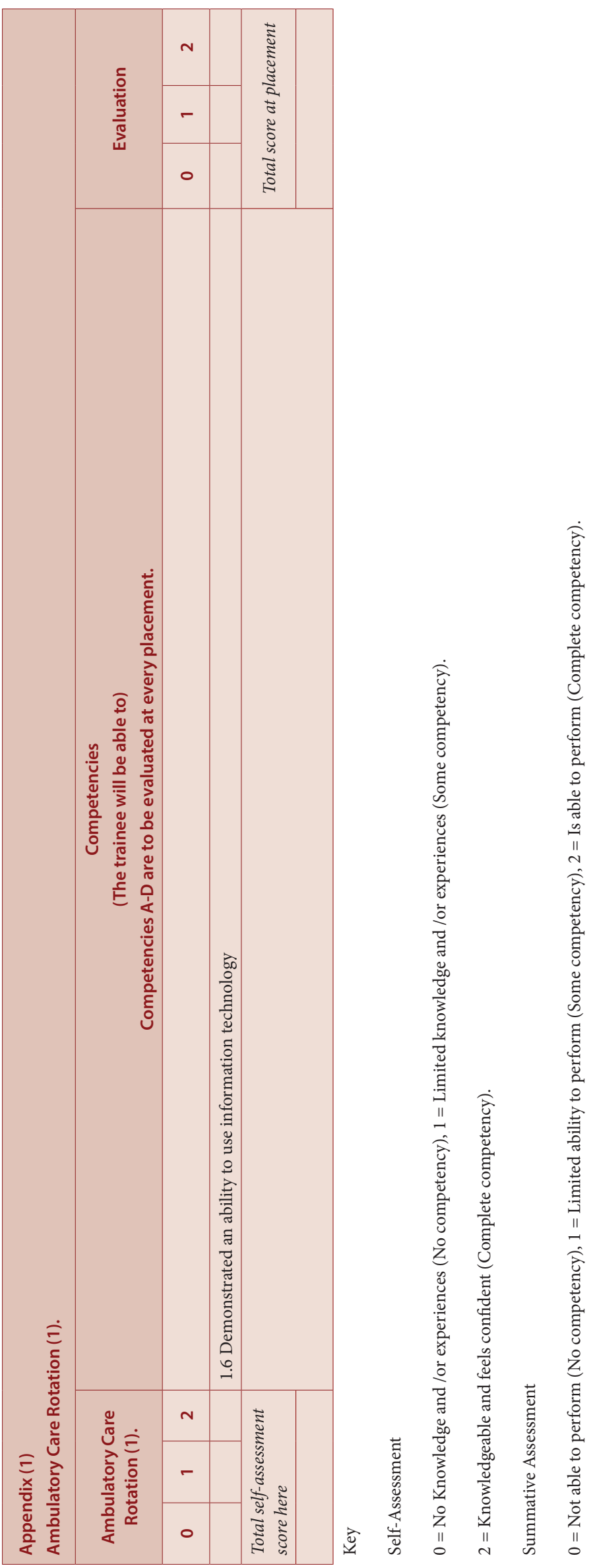




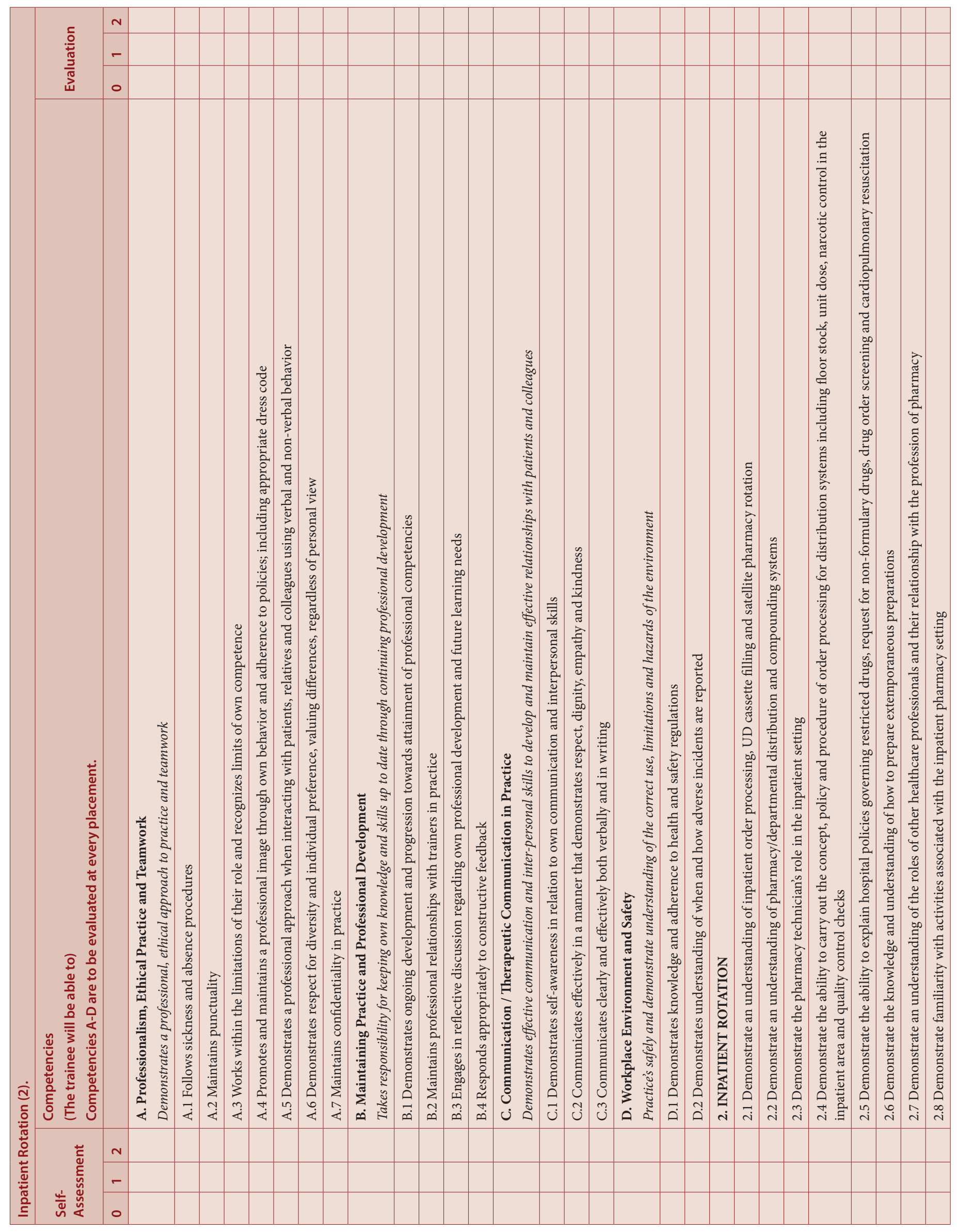




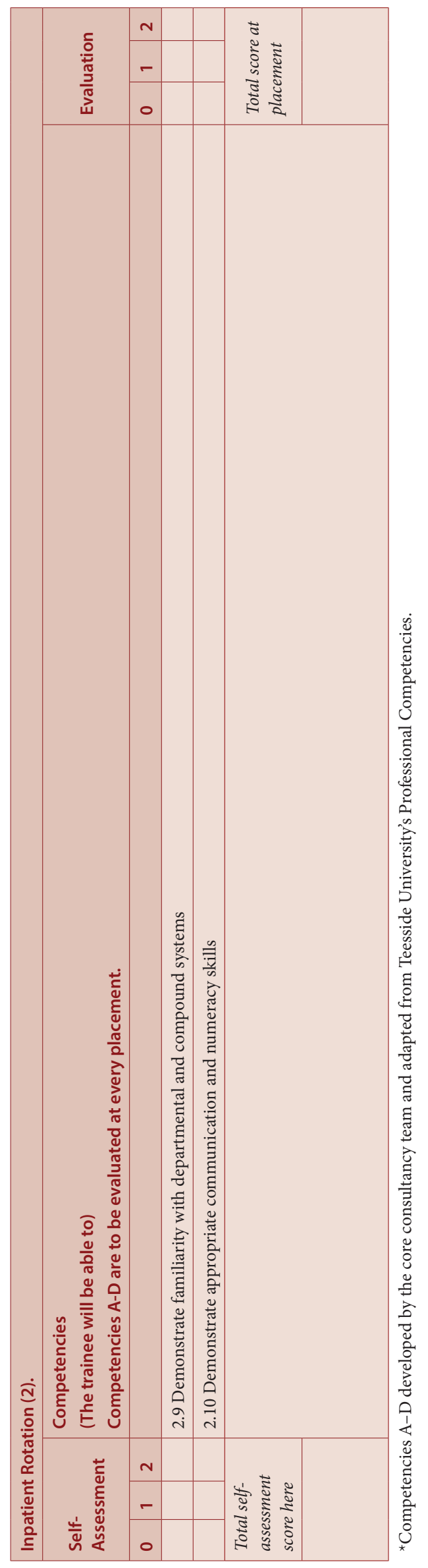




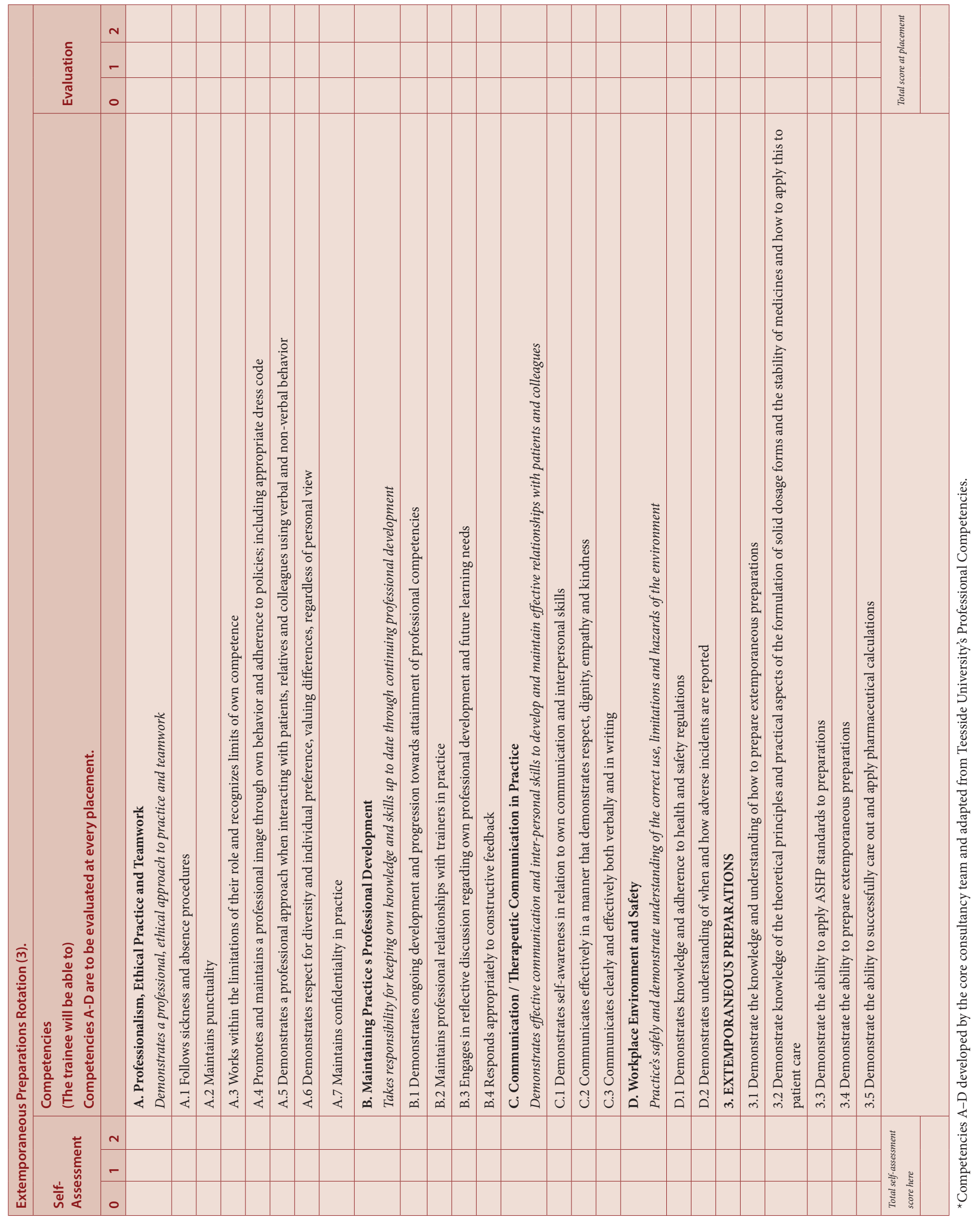




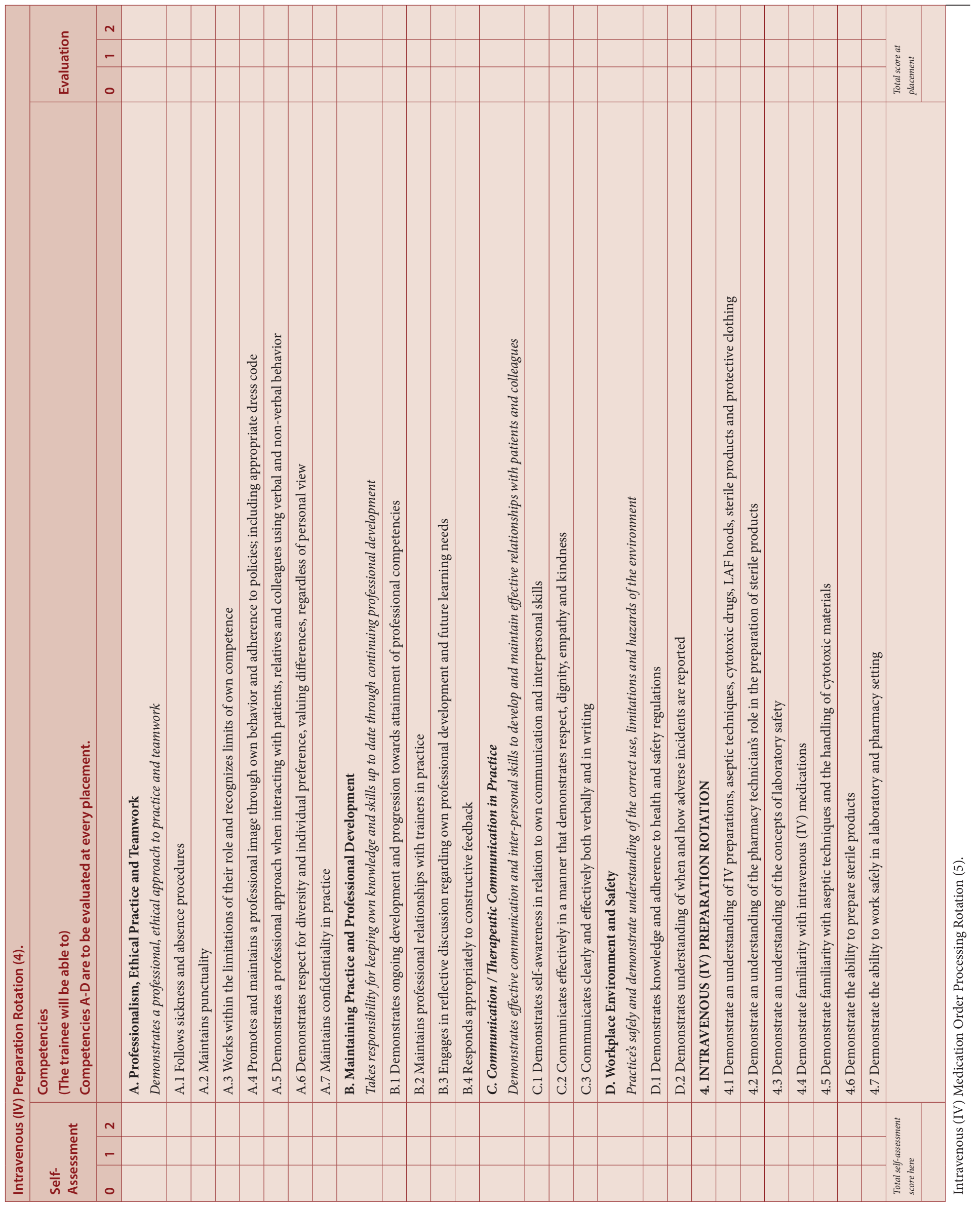




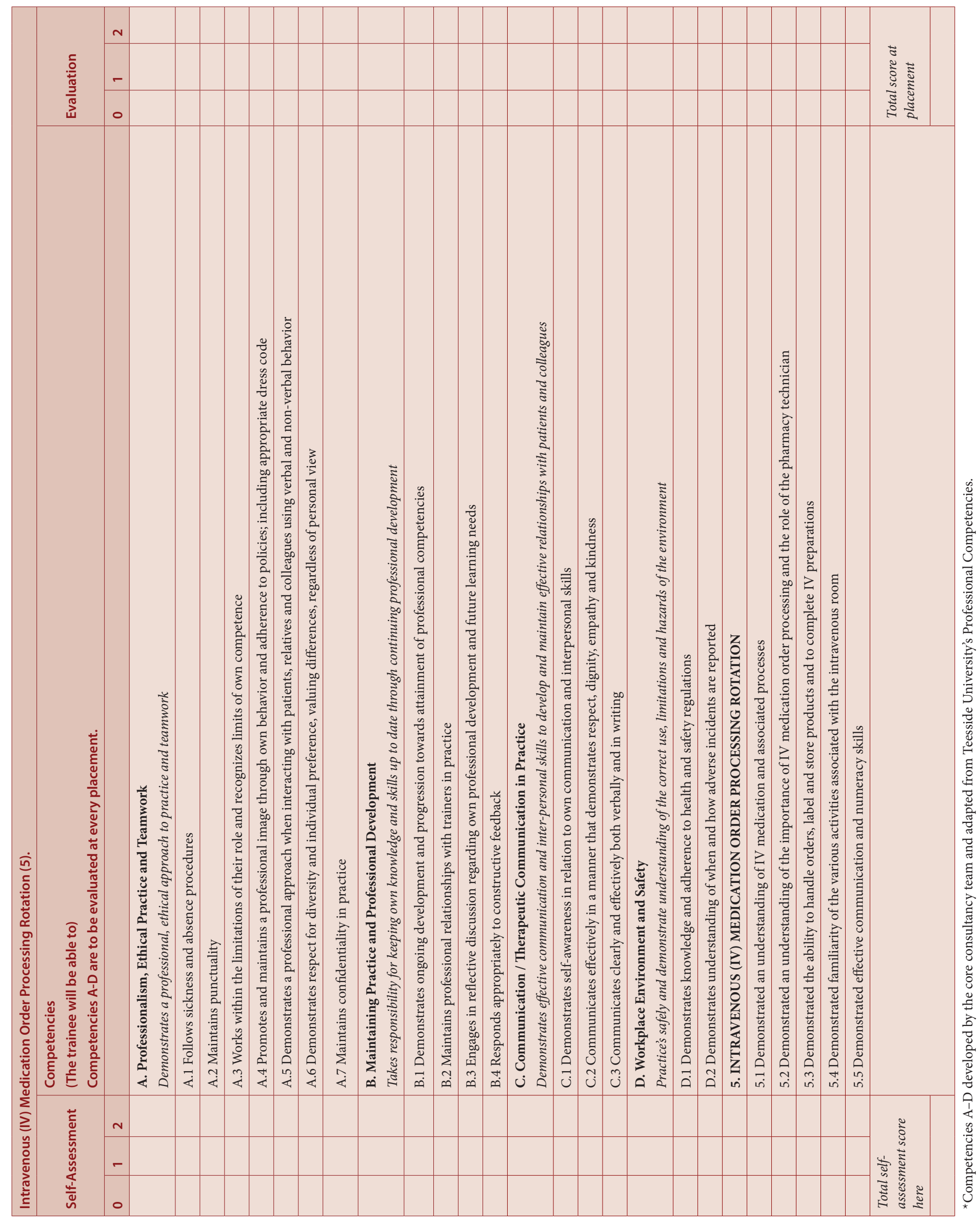




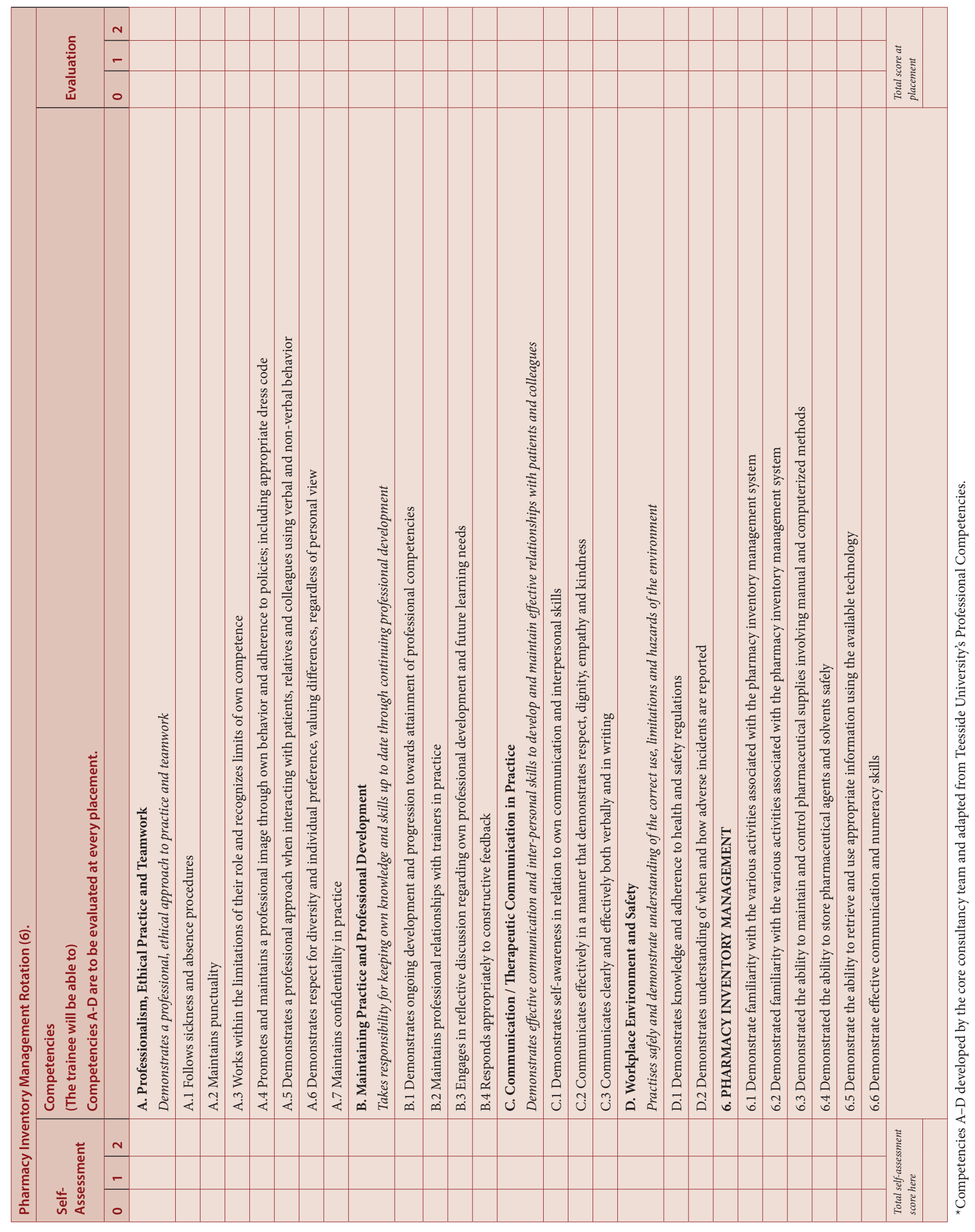




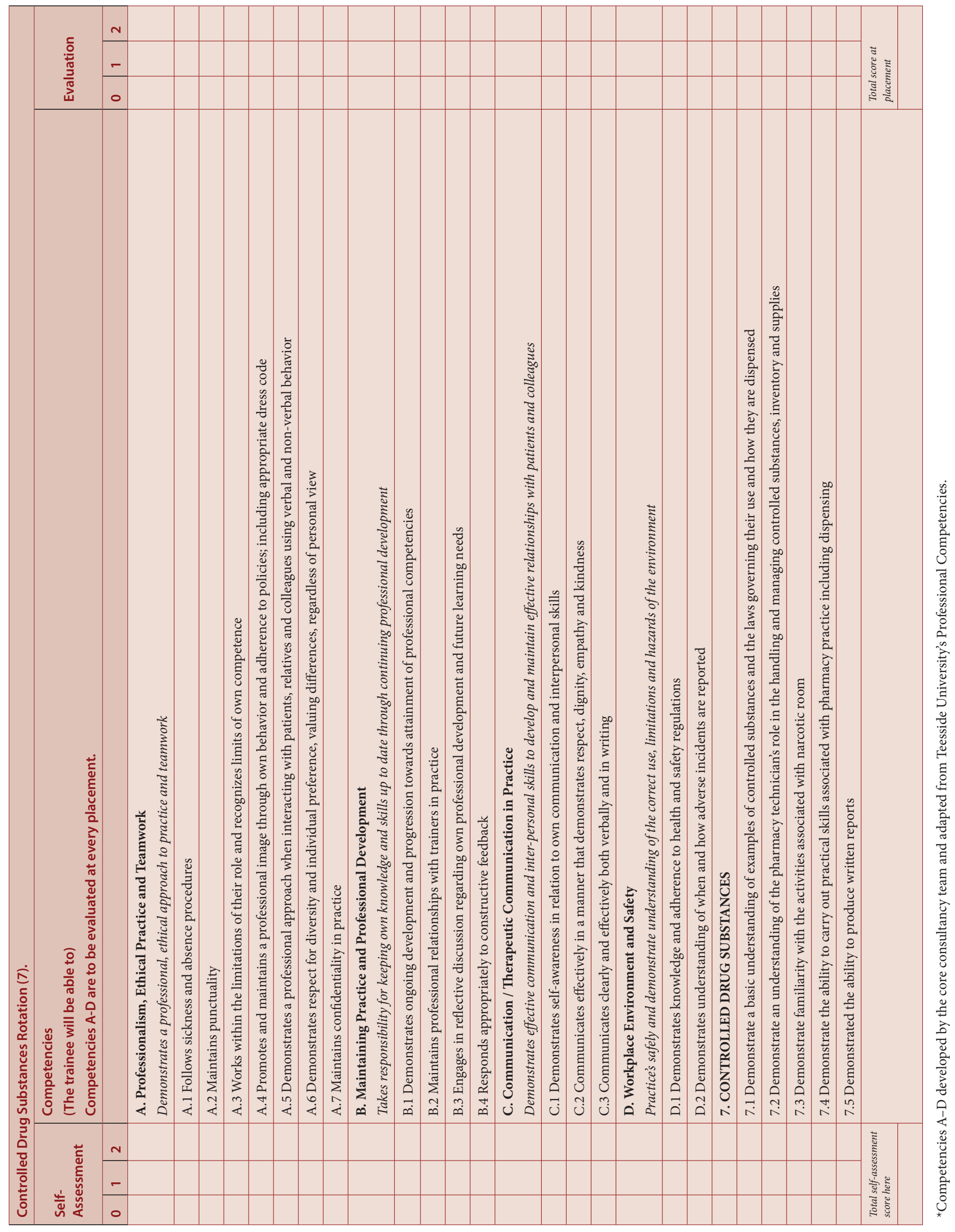




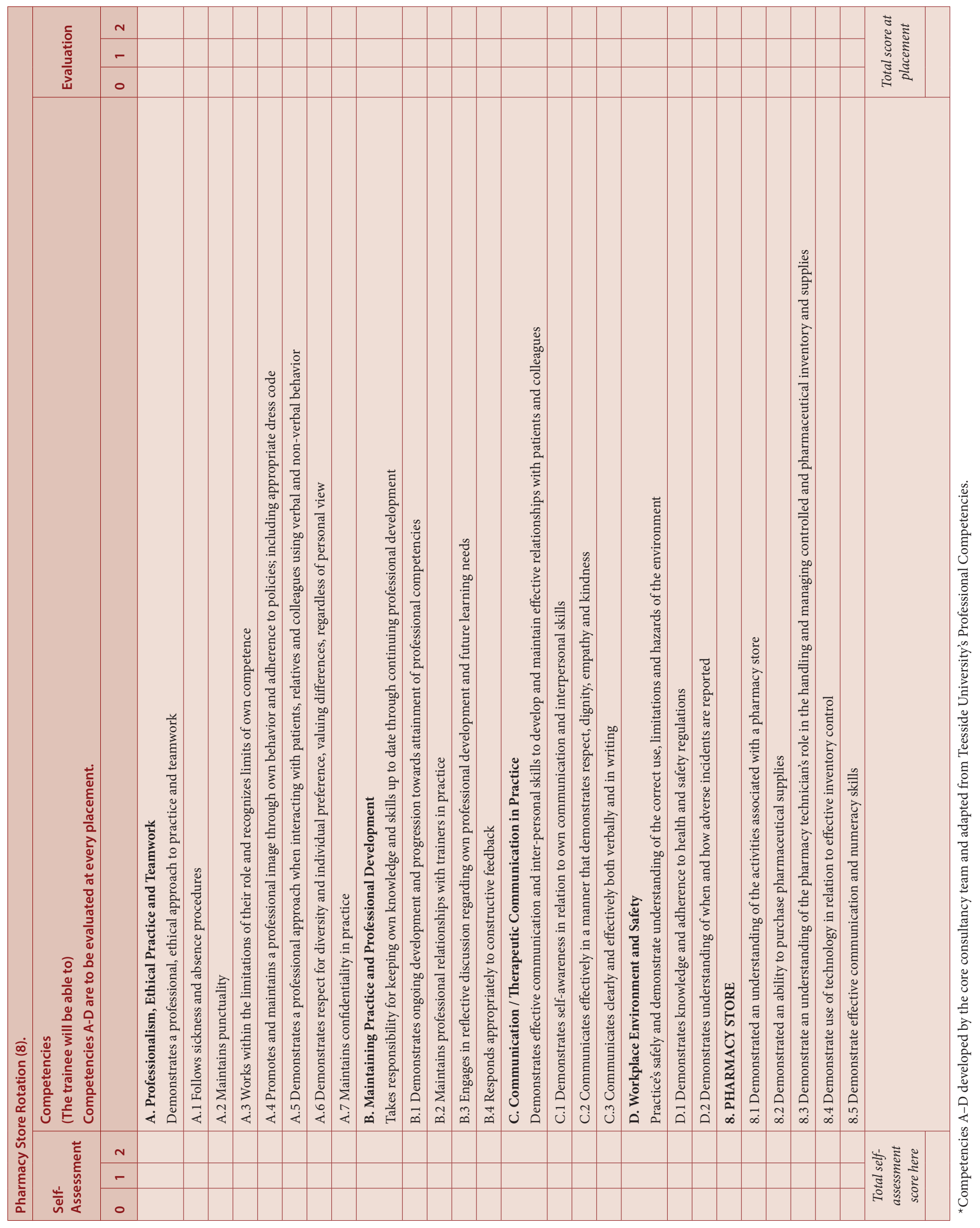




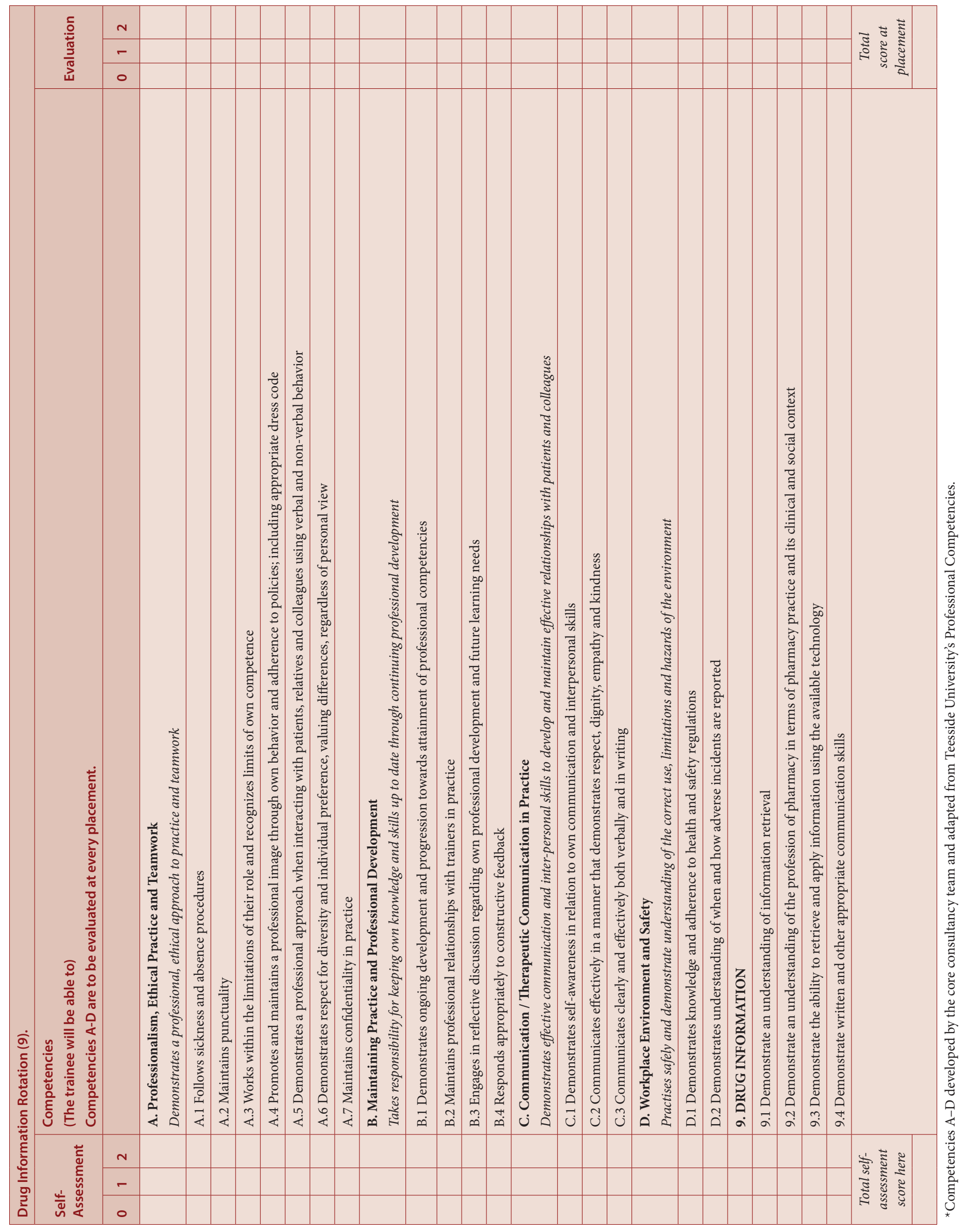




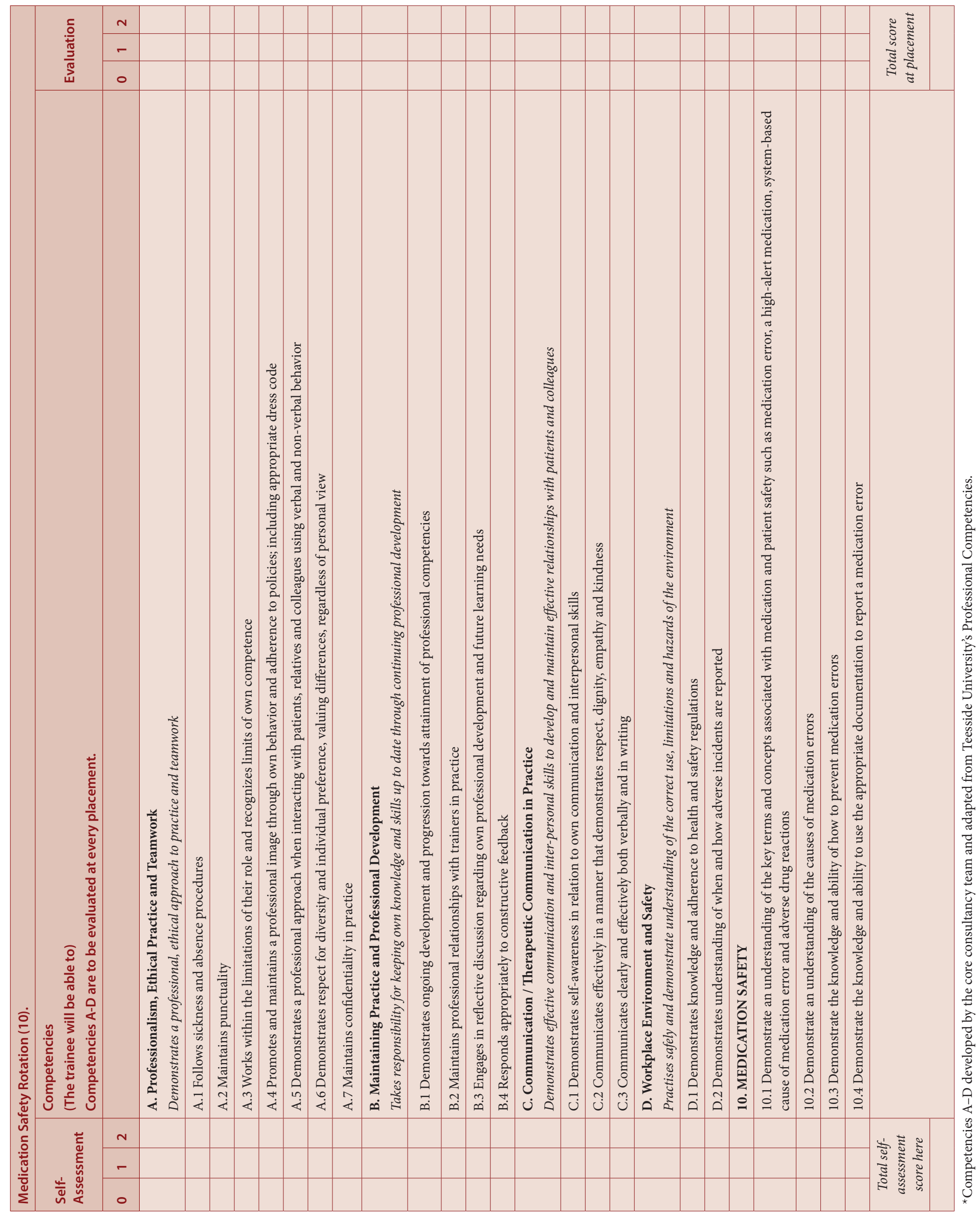




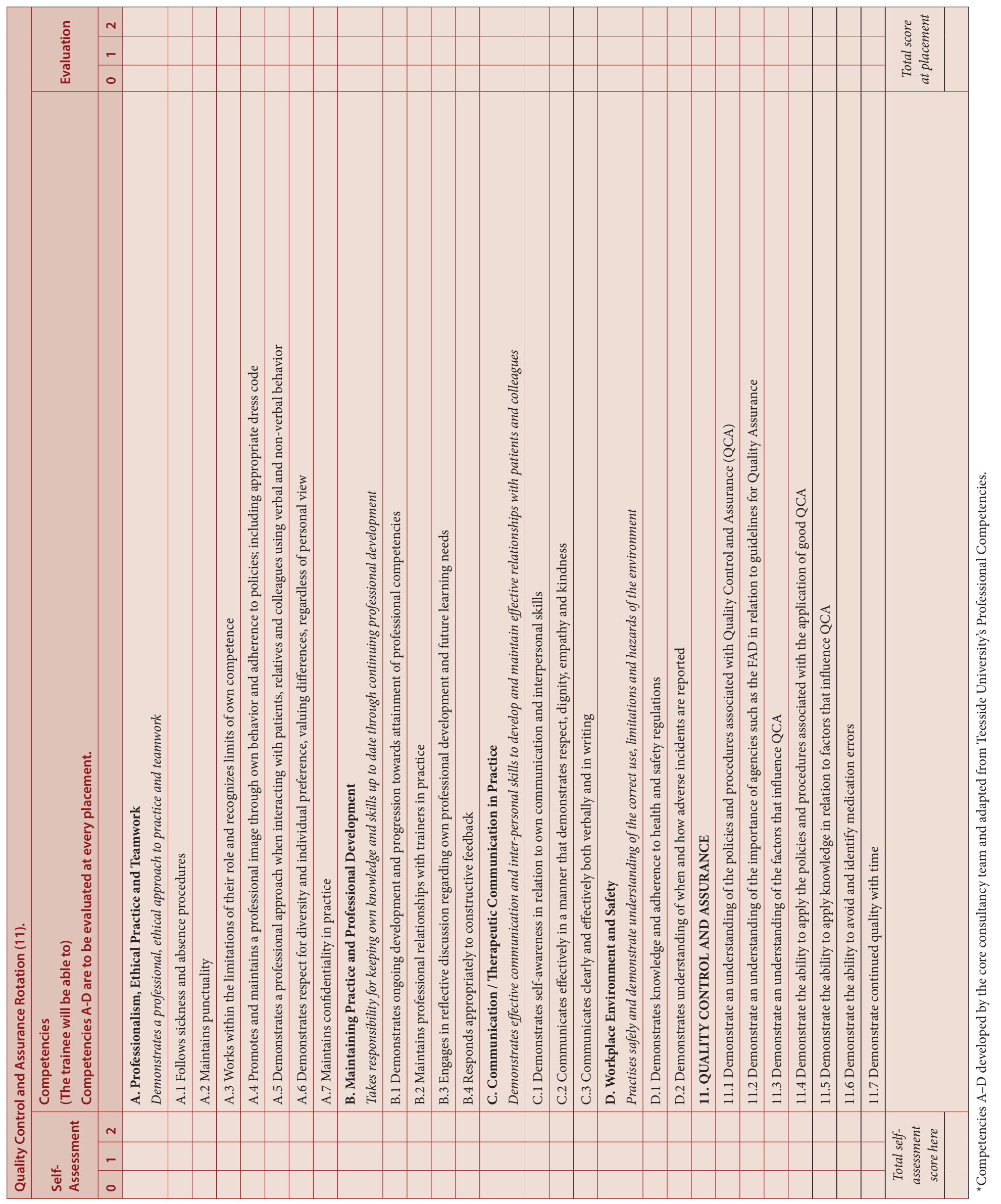

